\title{
Catalytic antibodies and enzyme inhibitors
}

\author{
Kim D. Janda \\ The Scripps Research Institute \\ Departments of Molecular Biology and Chemistry \\ 10666 N. Torrey Pines Road \\ La Jolla, California 92037
}

\begin{abstract}
Catalytic antibodies or abzymes as we have termed them have generated an avalanche of "forecasts and predictions" concerning their future applications. This, because in principle their only limitations are the designer's creativity and one's ability to access the entire immune systems repertoire. Keeping these so-called predictions in mind, we have sought out a truly formidable test for our de novo catalyst program. That being the creation of catalytic antibodies that have no enzymatic or synthetic catalyst equivalent. An antibody is reported which catalyzes a highly disfavored ring closure reaction with exquisite stereospecificity. The design and synthesis of peptidomimetic enzyme inhibitors continues to be an active area of research. Such compounds have proven useful in elucidating mechanisms of catalysis and as therapeutic agents. The discovery that the human immunodeficiency virus encodes an aspartic protease (HIV PR) vital for its propagation has brought this protein under intense scrutiny. In this regard, the development of compounds which inhibit the HIV PR has been particularly rapid. Herein we report on a new amide bond replacement, $\psi\left[\mathrm{PO}_{2}-\mathrm{CH}_{2} \mathrm{~N}^{+}\right]$which we term an "exploding transition-state analogue". Incorporation of this unit in peptide sequences and its potent, slow-binding inhibition of the HIV protease is discussed.
\end{abstract}

A considerable amount of effort has been focused on the development of efficient catalysts for the synthesis or modification of complex molecules. Two methodologies have generally been applied in these endeavors; protein and synthetic ligand binding catalysts. To attack such problems, we have recruited antigen induced catalysts from the immune system. ${ }^{1}$ These catalytic antibodies or abzymes as we have termed them have generated an avalanche of "forecasts and predictions" concerning their future applications. This, because in principle their only limitations are the designer's creativity and one's ability to access the entire immune systems repertoire. Keeping these so-called predictions in mind, we have sought out a truly formidable test for our de novo catalyst program. That being the creation of catalytic antibodies that have no enzymatic or synthetic catalyst equivalent. 2

Ring-forming reactions are important and common processes in organic chemistry. Almost twenty years ago J.E. Baldwin supplied a specific set of "favored" and "disfavored" rules for certain closings of 3-to 7membered rings. 3 The physical basis of these guidelines was formulated based on stereochemical requirements of the transition states for the various ring closure processes. Wherein favored pathways are those in which the length and nature of the linking chain enable the terminal atoms to achieve the proper geometrys for reaction, and disfavored cases require severe distortion of bond angles. Many cases in the literature are in substantial accord with Baldwin's rules, both experimentally and theoretically. 3,4

The skeletal structures of a number of bioactive marine natural products are found to contain $\mathrm{O}$ heterocyclic rings. 5 Of particular importance are the ubiquitous tetrahydropyrans, towards the synthesis of which much work has been done. ${ }^{6}$ One attractive strategy reduces to a regioselective 6 -endo-tet-ring opening of an epoxide by an internal nucleophilic oxygen (scheme I). However, conventional considerations (Baldwin's rules) suggest the 5-exo-tet mode of cyclization as the preferred pathway, (scheme I). Indeed, experimental evidence confirms this wherein the tetrahydrofuran system is the exclusively observed product. A specifically tailored catalytic antibody could provide a means for obtaining the desired, yet disfavored 6-endo-tet adduct. Hence, a catalytic regio-controlled detour, and thus a possible general methodology for the re-routing of disfavored ring closure reactions.

The concept on which we relied to achieve this selectivity is shown in scheme I, which depicts a scenario of an acid-catalyzed cyclization of hydroxyl epoxide 1. Based on our "bait and switch" principle", the problem reduces to the design of a hapten which could induce a regiospecific negatively charged participatory amino acid in the binding pocket of an antibody. According to this concept, a negative charge when strategically placed adjacent to the epoxide unit should act as a selective stabilizing element 
for the $\mathrm{C}-\mathrm{O}$ bond as it proceeds to rupture. In this scenario, endo ring closure would proceed to produce the so-called disfavored heterocycie 5 , via transition state $\mathbf{3}$, in which the developing electron-deficient orbital on carbon atom 6 ' would be stabilized by the negatively charged amino acid moiety. The alternative pathway of exo ring closure, leading to the smaller ring 4 , and proceeding via transition state 2 , in which the incipient positive charge would accumulate on carbon 5', would be expected to be less favored by the antibody. While we have shown an acid induced ring closure, for 2 or 3 (scheme I), a based induced antibody ring closure would also be expected to lead selectively to endo product 5 rather than the exo product 4 as can be deduced by analogous arguments. It should be stressed that an acid or base initiated ring closure is of little consequence. The main point is that in the absence of a regioselective antibody stabilizing element, ring closure will lead to the Baldwin predicted product.

Hapten 6, (scheme I) was designed in accordance with the concepts described above. It possesses the required regiospecific cationic charge, which should induce a complementary negative charge in the binding pocket of the antibody. Of further merit is the negatively charged oxygen atom. This anionic atom may also induce participatory amino acid residue(s) which may assist in the acid catalyzed ring opening of the epoxide. Lastly, such a multicharged hapten may facilitate ease of product release.

$\mathrm{N}$-oxide 6 was coupled to Keyhole Limpet Hemocyanin $(\mathrm{KLH})$ and the conjugate was used to immunize $129 \mathrm{IX}^{+}$mice for production of monoclonal antibodies; 8 and from this process a total of 26 hybridomas were obtained. All 26 of these highly purified antibodies at a concentration of $20 \mathrm{uM}$ were initially screened against racemic epoxy-alcohol 1a $(1.2 \mathrm{mM})$ in an aqueous assay system (50 mM PIPES, pH 6.5), and product formation of racemic tetrahydrofuran $4 \mathbf{a}$ and tetrahydropyran 5 a was monitored by reverse phase HPLC chromatography. In our study, 2 of the 26 antibodies were identified as regioselective catalysts for the formation of 5a. These 2 antibodies (26D9 and 17F6) were tested further for their potential stereospecificities, this in separate experiments using a normal phase HPLC column of chiral preparation. Under these conditions both enantiomers of 1a were separable, as were both pairs of stereoisomers of 4a and 5a. Again, racemic epoxy-alcohol 1a was employed as the substrate, however, now a $95 \%$ hexane/5\% PIPES buffer solution was utilized as the assay medium. ${ }^{9}$ From these two hybridomas, abzyme 26D9 was deemed to be the most stereoselective. Quite amazingly, it utilized only one of the two enantiomers of 1a and thereby selectively forms only one of the two stereoiosmers of $5 \mathrm{a}$. Because of 26D9's remarkable regio and stereoselectivities, further kinetic studies were performed.

Abzyme 26D9 initial rate of ring closure measured as a function of substrate 1a concentrations followed Michaelis-Menten kinetics, a finding consistent with pre-equilibrium substrate binding, a regio and stereospecific intramolecular nucleophilic attack of alcohol on the epoxide, and product dissociation. The $\mathrm{K}_{\mathrm{m}}, \mathrm{V}_{\max }$, and $\mathrm{k}_{\mathrm{cat}}$ were found to be $356 \mathrm{uM}, 4.6 \times 10^{-6} \mathrm{~min}^{-1}$, and $0.91 \mathrm{~min}^{-1}$ respectively. Comparison of $k_{\text {cat }} / k_{\text {uncat }}$ (the ratio of the rates of the catalyzed and uncatalyzed reactions) are typically made in antibody catalyzed reactions. This, to provide an index of measure as to the "rate acceleration" provided by the abzyme. In our case such a comparison was not possible, since the uncatalyzed rate of formation of the 6-membered ring 5a was undetectable under our assay conditions. This latter result, again in accordance with Baldwin's rules.

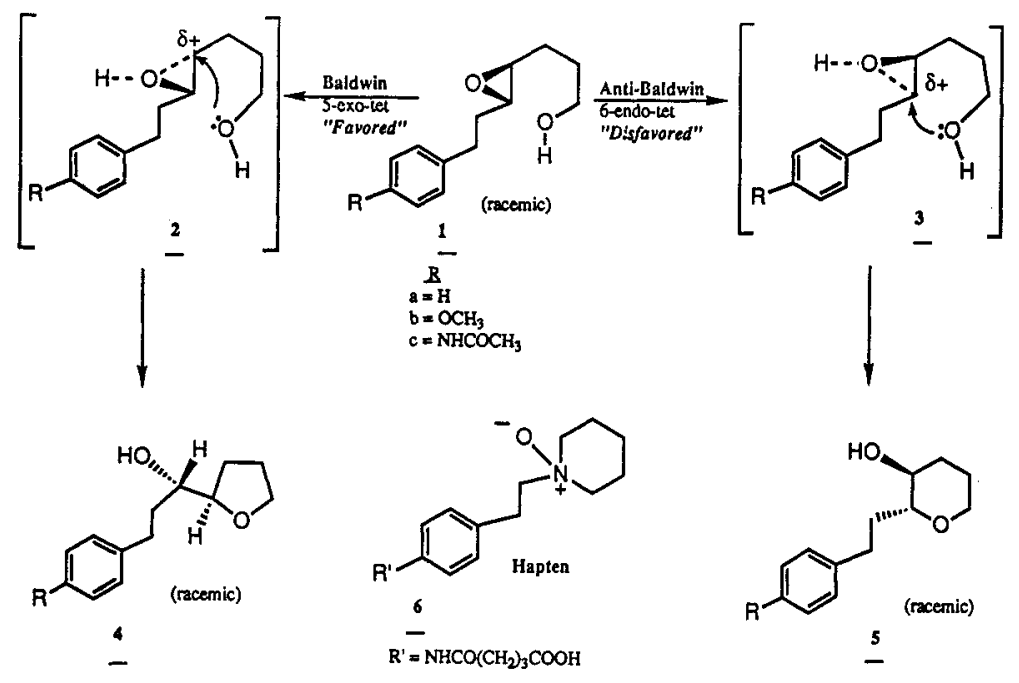


An unprecedented achievement in de novo catalyst procurement has been accomplished. Wherein we have created catalytic antibodies which have no enzymatic or synthetic equivalents. The novel properties of the abzymes generated in our study are their ability to catalyze a highly disfavored chemical process while also providing a chiral environment for the kinetic resolution and processing of stereochemically impure molecules encountered in the reaction. The latter ability being not of programmed hapten design but rather a stereochemical segregation process inherent in the immune system.

The total synthesis of complex natural products often requires the use of a wide variety of reagents. In addition, delicate functional group manipulations as well as regio- and stereo-chemical control is usually necessary. We envision singular catalysts performing such multifunctional tasks to bypass current strategies for obtaining these compounds. The antibodies we have described are both regio- and enantioselective catalysts. Moreover, they function equally well in aqueous or water-organic interfaces. We would suggest these multifunctional catalytic antibodies to be a starting point for the simplification of elaborate synthetic routes typically required to reach important synthetic targets.

The design and synthesis of peptidomimetic enzyme inhibitors continues to be an active area of research. Such compounds have proven useful in elucidating mechanisms of catalysis and as therapeutic agents. ${ }^{10}$ The discovery that the human immunodeficiency virus encodes an aspartic protease (HIV PR) vital for its propagation has brought this protein under intense scrutiny. ${ }^{11,12}$ In this regard, the development of compounds which inhibit the HIV PR has been particularly rapid. ${ }^{13}$

It seemed rational that an effective modification of the phosphonamidate structure 7, (figure 1), wellknown in protease inhibition, 14 would be to include additional features along the reaction coordinate for amide hydrolysis. The insertion of a methylene spacer between phosphorus and nitrogen produces the nonhydrolyzable moiety 8 , (figure 1 ) which is likely a zwitterion near physiological $\mathrm{pH}$. This construct could be representative of a late transition state/early product formation for amide bond cleavage in mimicking both the tetrahedral hydrate and departing amine 9, (figure 1). Its incorporation into a peptide backbone affords what we term an "exploding transition state analogue". 15

In analogy with the hydroxyethylamine surrogate utilized by Rich, et. al. ${ }^{16}$ the scissile $\mathrm{P}_{1}-\mathrm{P}_{1}{ }^{\prime}$ bond (notation of Schechter and Berger ${ }^{17}$ ) of the HIV PR p17/p24 substrate sequence was replaced with Phe $\psi\left[\mathrm{PO}_{2} \mathrm{CH}_{2} \mathrm{~N}^{+}\right]$Pro. An expedient synthesis of the pseudoheptapeptide is outlined in scheme II. The compound was obtained as separated $R$ and $S$ isomers (13R and 13S) at the $P_{1}$ benzylic position. ${ }^{18}$

The inhibition of synthetic HIV PR ${ }^{19}$ was measured using Lys-Ala-Arg-Val-Nle-pNO${ }_{2}$ Phe-Glu-Ala-Nle$\mathrm{NH}_{2}{ }^{20}$ adapted to an isocratic HPLC assay $\left(\mathrm{K}_{\mathrm{m}}=434 \pm 25 \mu \mathrm{M}, \mathrm{k}_{\text {cat }}=10 \pm 0.2 \mathrm{~s}^{-1}\right.$; Table 1). It was apparent that 13R was potent in the nanomolar concentration range. Upon closer examination, the inhibition was observed to be time-dependent. The initiation of reactions with either enzyme or substrate gave burst and lag transients, respectively. In light of (1) the chemical nature of the $\psi\left[\mathrm{PO}_{2} \mathrm{CH}_{2} \mathrm{~N}^{+}\right]$ functionality, (2) the establishment of equilibrium after enzyme-inhibitor preincubation and (3) the equivalence of steady-state rates attained in burst and lag experiments, it is likely that the inhibitor binds in a reversible, noncovalent fashion. Hence, $7 \mathbf{R}$ was studied as a slow-binding inhibitor. ${ }^{21}$

The final steady-state levels of inhibition revealed competitive inhibition. Since the values derived from an analysis of burst-transient progress curves satisfied required criteria, the mechanism of inhibition is in accord with the model illustrated in scheme III. ${ }^{22}$ The data are shown in Table I. The $\mathrm{K}_{i}^{*}$ of $8 \mathrm{nM}$ for 13R ranks it highly as an HIV PR inhibitor and results in an inhibited enzyme of relatively long lifetime. Interestingly, $\mathrm{K}_{\mathbf{i}}^{*}$ doubled at $\mathrm{pH} 4.7$ in contrast to the $\mathrm{pH}$ profile of simple phosphinates. 23 The $13 \mathrm{~S}$ isomer, which binds $>6 \times 10^{3}$-fold less tightly, also demonstrates slow-binding behavior. This is somewhat surprising given that the slow-binding phenomenon generally shows a strong stereochemical preference. 24 It is premature to speculate concerning protonation effects or conformations enforced by $\psi\left[\mathrm{PO}_{2} \mathrm{CH}_{2} \mathrm{~N}^{+}\right]$ and adopted at the HIV PR active site.

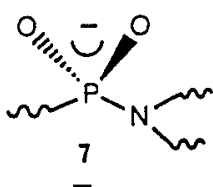

$-$
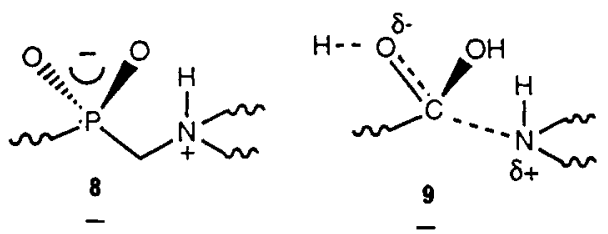
TABLE I. Kinetic Parameters for HIV PR Inhibitors ${ }^{a}$

\begin{tabular}{lcc}
\hline Parameter & 13R & 13Sc \\
\hline $\mathrm{K}_{\mathrm{i}}^{*}(\mathrm{nM})$ & $8.2 \pm 0.4$ & $54 \pm 3\left(\times 10^{3}\right)$ \\
$\mathrm{K}_{\mathrm{i}}(\mathrm{nM})$ & $82 \pm 8$ & $585 \pm 60\left(\times 10^{3}\right)$ \\
$\mathrm{k} 5\left(\mathrm{~min}^{-1}\right)$ & $0.15 \pm 0.025$ & $0.26 \pm 0.045$ \\
$\mathrm{k} 6\left(\mathrm{~min}^{-1}\right)$ & $0.017 \pm 0.0020$ & $0.026 \pm 0.0031$ \\
$\mathrm{k} 5 / \mathrm{k}_{6}$ & $9 \pm 1$ & $10 \pm 1$ \\
$\mathrm{t} 1 / 2(\mathrm{EI})(\min )$ & $40 \pm 5$ & $26 \pm 3$
\end{tabular}

aptermined at $23^{\circ} \mathrm{C}$ in $100 \mathrm{mM}$ MES, $1 \mathrm{mM}$ EDTA, $1 \mathrm{mM}$

DTT, $200 \mathrm{mM} \mathrm{NaCl}, 0.1 \%$ Triton X-100, pH 6.2; 1 nM enzyme,

$1500 \mu \mathrm{M}$ substrate. $b_{\text {weighted averages from stepwise analysis }}$

of five progress curves $\left(\mathrm{K}_{i}{ }^{*}\right.$ also evaluated from a complete

double reciprocal experiment). ${ }^{c_{\text {weighted averages from }}}$

stepwise analysis of three progress curves.

Observations suggest the driving force for the time-dependent inhibition is localized in the Phe $\psi[\mathrm{PO}$ $\left.2 \mathrm{CH}_{2} \mathrm{~N}^{+}\right]$Pro subunit. Remarkably, the dipeptide analogue $14 \mathrm{R}$ is a competitive inhibitor $\left(\mathrm{K}_{\mathrm{i}}^{*}=270\right.$ $\mu \mathrm{M}$ ) which does not equilibrate rapidly with the enzyme. While the peptide periphery provides specific interactions which ultimately lead to high affinity, it is not solely responsible for the changes occurring in the pre-steady-state. The events which transpire in the slow equilibration to a tightened EI* complex are not clear, but $\psi\left[\mathrm{PO}_{2} \mathrm{CH}_{2} \mathrm{~N}^{+}\right]$seems a powerful design for a transition state, reaction intermediate, or tetrahedral collected product. 25

Further kinetic characterization, development of potential pharmacologically useful HIV PR inhibitors and application of $\psi\left[\mathrm{PO}_{2} \mathrm{CH}_{2} \mathrm{~N}^{+}\right]$to other proteolytic enzymes are under investigation.

Acknowledgments. This work was supported by grants from the National Institutes of Health and the National Science Foundation. We also gratefully acknowledge the A.P. Sloan Foundation for a fellowship.

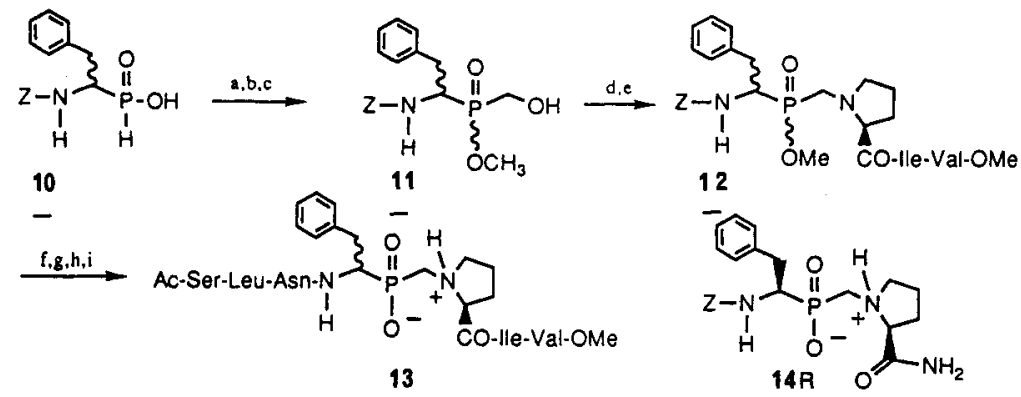

'Reagents and conditions: (a) TMS-Cl, $\mathrm{Et}_{3} \mathrm{~N}, \mathrm{CH}_{2} \mathrm{Cl}_{2}, 5^{\circ} \mathrm{C}$, 3h; (b) $\mathrm{CH}_{2} \mathrm{O}, 3 \mathrm{~h}$; (c) $\left(\mathrm{CH}_{3} \mathrm{O}\right)_{3} \mathrm{P}$, $90^{\circ} \mathrm{C}, 3 \mathrm{~h},(45 \%)$; (d) $\mathrm{CF}_{3} \mathrm{SO}_{2} \mathrm{Cl}, \mathrm{DMAP}, \mathrm{Et}_{3} \mathrm{~N}, \mathrm{CH}_{2} \mathrm{Cl}_{2},-50^{\circ} \mathrm{C}, 3 \mathrm{~h}$; (e) H-Pro-Ile-Val-OMe, THF, 3h, (65\%); (f) $\mathrm{H}_{2}$, Pd/C, MeOH/ethyl acetate, 3h; (g) Ac-Ser(Bzl)-Leu-Asn-OH, EDC, HOBT, ethyl acetate/DMF, $5^{\circ} \mathrm{C}, 24 \mathrm{~h},(75 \%)$; (h) $\mathrm{H}_{2}, \mathrm{Pd}(\mathrm{OH})_{2}, \mathrm{MeOH} /$ acetic acid, $16 \mathrm{~h}$, (45\%); (i) t-butylamine, $45^{\circ} \mathrm{C}, 24 \mathrm{~h},(25 \%)$.

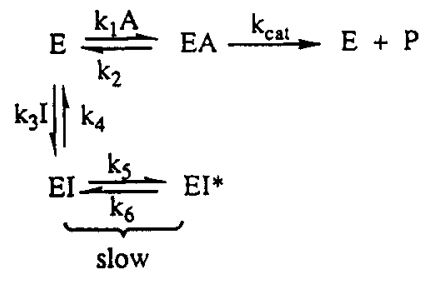


Bibliography

1. Lerner, R.A.; Benkovic, S.J.; Schultz, P.G., Science 252, 659-667 (1991).

2. The following is an account of our previously described work. Janda, K.D.; Shevlin, C.G.; Lerner, R.A., Science 259, 490-493 (1993).

3. (a) J. March, Advanced Organic Chemistry (Wiley, New York, ed. 3, 1985), pp. 187, 188. (b) Baldwin, J.E., J. Chem. Soc. Chem. Commun. 734 1976 (1976).

(c) Baldwin, J.E.; Wsik, M.S., Tetrahedron 19, 2929 (1982).

4. Beak, P. Acc. Chem. Res. 25, 215 (1992).

5. For some recent reviews, see (a) Faulkner, D.J., Nat. Prod. Rep. 3, 1 (1986); 1, 251, 551 (1984). (b) Polyether Antibotics: Naturally Occurring Acid Ionophores; Westley, J.W., Ed.; Marcel Dekker: New York, 1982.

6. For examples, see the following and references therein: (a) Nicolaou, K.C.; Prasad, C.V.C.; Somers, P.K.; Hwang, C.-K., J.Am. Chem. Soc. 111, 5330 (1989); (b) ibid., p. 5355; (c) Nicolaou, K.C.; Duggan, M.E.; Hwany, C.-K., Somers, J. Chem. Soc. Commun. 1985, 1359 (1985).

7. For an example see the following and references therein: Janda, K.D.; Weinhouse, M.I.; Danon, T.; Pacelli, K.A.; Schloeder, D.M. L. Am. Chem. Soc., 113, 5427-5434 (1991).

8. Kohler, G.; Milstein, C., Nature 256, 495 (1975).

9. Ashley, J.A.; Janda, K.D., J. Org. Chem. 57, 6691-6693 (1992).

10. (a) Rich, D.H. In Comprehensive Medicinal Chemistry: Sammes, P. G., Ed.; Pergamon: Oxford, 1990; Vol. 2, pp 391-441. (b) Dingle, J. T., Gordon, J.L., Eds. Research Monographs in Cell and Tissue Physiology: Barrett, A.J., Salvesen, G., Eds.; Elsevier: Amsterdam, 1986; Vol. 12 Proteinase Inhibitors.

11. Kramer, R.A.; Schaber, M.D.; Skalka, A.M.; Ganguly, K.; Wong-Staal, F.; Reedy, E.P., Science 231, 1580-1584 (1986).

12. Kohl, N.E.; Emini, E.A.; Schleif, W.A.; Davis, L.J.; Heimbach, J. C.; Dixon, R.A.F.; Scolnick, E.M.; Sigal, I.S., Proc. Natl. Acad.Sci. U.S.A. $\underline{85}$, 46864690 (1988).

13. Huff, J.R., J.Med. Chem. 34, 2305-2314 (1991). It should be noted that structure 15 in Table III is depicted incorrectly and is actually a secondary carbocyclic phosphinate.

14. (a) Bartlett, P.A.; Marlowe, C.K., Science 235, 569-571 (1987); (b) Bartlett, P.A.; Marlowe, C.K., Biochemistry 22, 4618-4624 (1983); (c) Thorsett, E.D.; Harris, E.E.; Peterson, E.R.; Greenlee, W.J.; Patchett, A.A.; Ulm, E.H.; Vassil, T.C., Proc. Natl. Acad. Sci. U.A.A. 79, 2176-2180 (1982); (d) Jacobsen, N.E.; Bartlett, P.A., J. Am. Chem. Soc. 103, 654-657 (1981).

15. The following is an account of our previously described work. Ikeda, S.; Ashley, J.A.; Wirsching, P.; Janda, K.D., J. Am. Chem. Soc. 114.7604 (1992).

16. Rich, D.H.; Green, J.; Toth, M.V.; Marshall, G.R.; Kent, S.B.H., J. Med. Chem. 33, 1285-1287 (1990).

17. Schechter, I; Berger, A., Biochem. Biophys. Res. Commun. 27 157-162 (1967). 
18. The $\mathbf{R}$ configuration corresponds to the stereochemistry of the natural (S)-1-amino acids. The $\mathbf{1 3}$ isomer was also independently synthesized from optically pure $\mathbf{1 0}$.

19. Schneider, J.; Kent, S.B.H., Cell 54, 363-368 (1988).

20. Richards, A.D.; Phylip, L.H.; Farmerie, W.G.; Scarborough, P.E.; Alvarez, A.; Dunn, B.M.; Hirel, P.-H.; Konvalinka, J.; Strop, P.; Pavlickova, L.; Kostka, V.; Kay, J., J. Biol. Chem, 265, 7733-7736 (1990).

21. Morrison, J.F.; Walsh, C.T. Adv. Enzymol. Relat. Areas Mol. Biol. 61, 201-301 (1987).

22. (a) Morrison, J.F.; Cleland, W.W., Biochemistry 22, 5507-5513 (1983).

(b) Duggleby, R.G.; Attwood, P.V.; Wallace, J.C.; Keech, D. B., Biochemistrv 21, 3364-3370 (1982).

23. (a) Grobelny, D.; Wondrak, E.M.; Galardy, R.E.; Oroszlan, S., Biochem. B iophys. Res. Commun 169, 1111-1116 (1990). (b) Dreyer, G.B.; Metcalf, B.W.; Tomaszek, T.A., Jr.; Carr, T.J.; Chandler, A.C., III; Hyland, L.; Fakhoury, S.A.; Magaard, V.W.; Moore, M.L.; Strickler, J. E.; DeBouck, C.; Meek, T.D., Proc. Natl. Acad.Sci. U.S.A. 86, 9752-9756 (1989).

24. (a) Kettner, C.A.; Shenvi, A.B., J. Biol. Chem. 259, 15106-15114 (1984);

(b) Bartlett, P.A.; Kezer, W.B., J.Am. Chem. Soc. 106, 4282-4283 (1984).

25. Hyland, L.J.; Tomaszek, T.A., Jr.; Meek, T.D., Biochemistry 30, 8454-8463 (1991). 